\title{
Pemodelan Bangkitan Pergerakan pada Perumahan Griya Citra Asri Kota Surabaya
}

\author{
Kurnia Hadi Putra ${ }^{1^{*}}$, Muhammad Reza Fikma Effendi ${ }^{1}$ \\ ${ }^{1}$ Program Studi Teknik Sipil, Fakultas Teknik Sipil dan Perencanaan, Institut Teknologi Adhi Tama Surabaya \\ Email: *kurnia_putra@itats.ac.id
}

\begin{abstract}
As an industrial city in west Surabaya exactly Margomulyo industrial area, Surabaya city has numerous housings to support people's needs such as Griya Citra Asri (GCA) residence. Consequently, the road performances are decreasing and eventually disrupt the activities and movement for both humans and goods from inside and outside the town, for instance traffic congestion, accident, and limited vehicle speed which does not meet the speed plan. Therefore, this research aimed at investigating the characteristics of trip among people living in this housing area. Besides, it was also intended for figuring out the model of trip generation of people at Griya Citra Asri Surabaya residence using multiple linear regression. The best model for movement generation obtained $Y=-0.808+0.156+0.083+0.166+0.665+0.165+0.170+0.091$ having $R 2=0.997$, $F$ count $=9966700$, in which $X 1=$ total family members, $X 2=$ total revenue, $X 3=$ total family members who are working, X4 = total family members who are schooling, X5 = total vehicles, X6 $=$ total cars, and X7 = total travel distances. Accordingly, there were 2 dominant factors affecting the trip generation at Griya Citra Asri Surabaya housing namely total family members who are schooling (X4) and total cars (X6).
\end{abstract}

Keywords: GCA Housing, movement generation, multiple linear regression

\begin{abstract}
ABSTRAK
Sebagai kota industri yang terletak di wilayah Surabaya barat yang bertempat di kawasan industri Margomulyo, kota Surabaya memiliki banyak perumahan untuk menunjang kebutuhan, salah satunya perumahan Griya Citra Asri Surabaya (GCA). Hal ini akan Menyebabkan menurunnya kinerja jalan yang berakibat pada gangguan aktivitas dan pergerakan manusia dan barang dari dalam maupun luar kota. berupa kemacetan, kecelakaan, dan berkurangnya kecepatan kendaraan yang tidak sesuai kecepatan rencana. Tujuan dari penelitian ini adalah untuk mengetahui karateristik perjalanan penduduk perumahan dan mengetahui model bangkitan perjalanan penduduk perumahan Griya Citra Asri Surabaya dengan metode regresi linear berganda. Model terbaik untuk bangkitan pergerakan pada perumahan Griya Citra Asri adalah $\mathrm{Y}=-0.808+0.156+0.083+0.166+0.665+0.165+0.170+$ 0.091 dengan $\mathrm{R}^{2}=0,997, \mathrm{~F}$ hitung 9966700 . Dimana $\mathrm{X} 1$ adalah jumlah anggota keluarga, X2 adalah jumlah pendapatan, X3 adalah jumlah anggota pekerja, X4 adalah jumlah anggota berkeluarga sekolah, X5 adalah jumlah motor, X6 adalah mobil, dan X7 adalah jumlah jarak tempuh perjalanan. Terdapat 2 faktor yang paling dominan dalam mempengaruhi bangkitan perjalanan di perumahan Griya Citra Asri Surabaya yaitu jumlah anggota keluarga bersekolah X4, jumlah mobil X6.
\end{abstract}

Kata kunci : Perumahan GCA, bangkitan pergerakan, regresi linear berganda.

\section{Pendahuluan}

Sebagai kota industri yang terletak di wilayah Surabaya barat yang bertempat di kawasan industri Margomulyo, kota Surabaya memiliki banyak perumahan untuk menunjang kebutuhan pemukiman warganya. Salah satu perumahan yang terdapat di kota Surabaya barat adalah perumahan Griya Citra Asri Surabaya (GCA) kelurahan Kandangan, Kecamatan Benowo, Kabupaten Surabaya. Banyak dari penduduk perumahan ini yang beraktivitas keluar dari lingkungannya untuk keperluan bekerja, bersekolah, berbelanja dan keperluan lainnya. Saat ini perumahan Griya Citra Asri mempunyai 800 unit rumah dan jumlah rumah yang sudah di tempati yaitu 650 unit.Di kelurahan Kandangan selain perumahan Griya Citra Asri terdapat beberapa perumahan lainnya yaitu "Bukit Citra Darmo I", "Bukit Citra Darmo II", "Citra Permata Regency", dll. 
Penelitian ini dilakukan untuk memperoleh jumlah perjalanan yang dibangkitkan pada penduduk perumahan Griya Citra Asri, karena keberadaan perumahan Griya Citra Asri dapat diramalkan dengan bangkitan. untuk menentukan model bangkitan perjalanan yang menimbulkan adanya karateristik yang berpengaruh terhadap bangkitan perjalanan khususnya di perumahan Griya Citra Asri Surabaya Barat. Dengan adanya perumahan Griya Citra Asri akan menimbulkan kemacetan arus lalu lintas karena bangkitan penduduk perumahan Griya Citra Asri melewati Jalan Raya Kandangan. Jalan Raya kandangan dikenal rawan kemacetan karena daerah perindustrian dimana terdapat banyak pabrik-pabrik di sekitarnya. Hal ini akan menyebabkan menurunnya kinerja jalan yang berakibat pada gangguan aktivitas dan pergeralan manusia dan barang dari dalam maupun luar kota.

Menurut media massa Berita Lima terjadi kemacetan ekstrim menuju arah masuk Kota Surabaya dari jalur Jalan Raya Kandangan hingga Manukan yang diakibatkan meningkatnya jumlah pengendara dari luar kota. Dengan adanya kemacetan tersebut pemerintah Kota Surabaya mengupayakan membuka jalan baru di Jalan Raya Sememi [1]. Gangguan bangkitan pergerakan arus lalu lintas berupa kemacetan, kecelakaan, berkurangnya kecepatan kendaraan yang tidak sesuai kecepatan rencana dan lain sebagainya [2].

\section{Metode}

\subsection{Lokasi Penelitian}

Penelitian ini di lakukan di perumahan Griya Citra Asri Surabaya, kelurahan kandangan, kecamatan benowo, kabupaten Surabaya. Adapun peta lokasi penelitian tersebut adalah sebagai berikut :

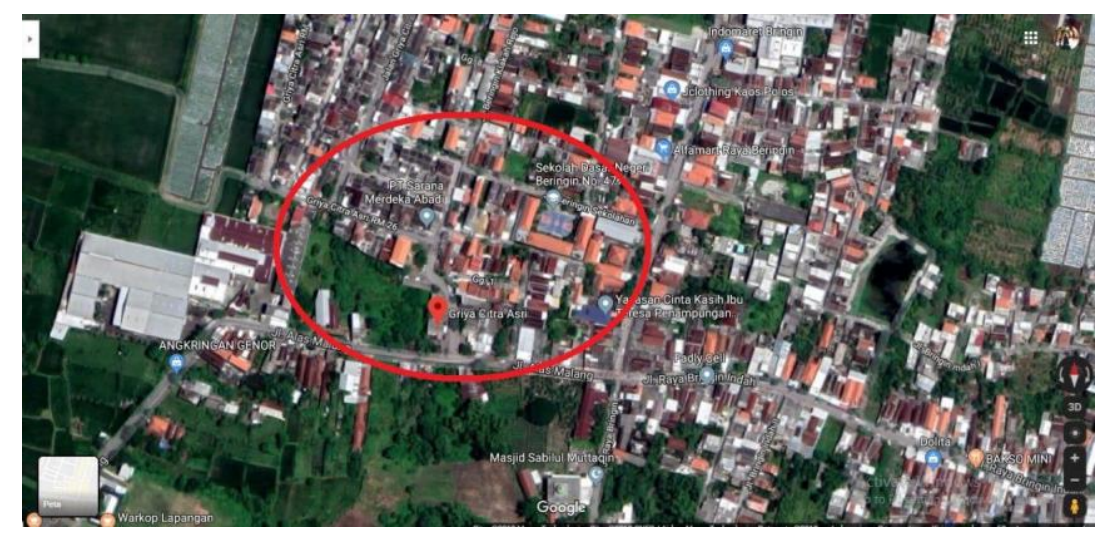

Gambar 1. Lokasi penelitian

\subsection{Tahapan Penelitian}

Metodologi penelitian merupakan suatu tahapan dalam melakukan penyusunan penelitian tugas akhir. Dalam penelitian ini diperlukan langkah-langkah sistematis agar tujuan pembahasan tidak menyimpang. Untuk membantu mempermudah langkah-langkah penelitian maka peneliti menggambarkan bentuk diagram alir pada Gambar 2.

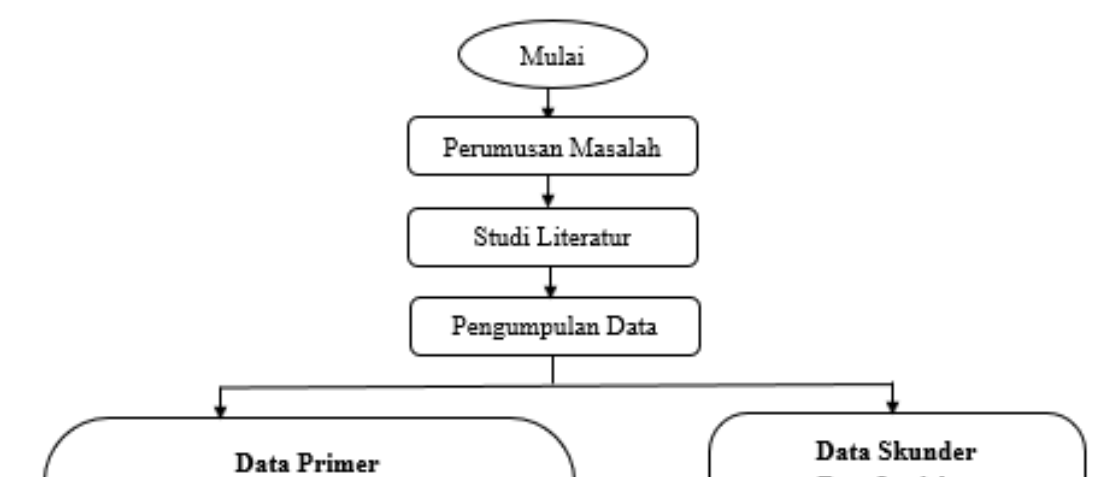




\section{Gambar 2. Diagram Alir Penelitian}

\subsection{Variabel Penelitian}

Variabel penelitian adalah segala sesuatu yang berbentuk apa saja yang di tetapkan oleh peneliti untuk di pelajari sehingga di peroleh informasi tentang hal tersebut, kemudian di tarik kesimpulan [3]. Variabel yang digunakan dalam penelitian yaitu variabel independen (bebas) dan variable terikat. a. Variabel Bebas

- Data jumlah anggota keluarga

- Data jumlah pendapatan rata-rata keluarga per bulan

- Data jumlah anggota keluarga bekerja

- Data jumlah anggota keluarga bersekolah

- Data jumlah motor

- Data jumlah mobil

- Data jumlah jarak tempuh perjalanan

\section{b. Variabel Terikat}

- Perjalanan anggota keluarga perhari di perumahan Griya Citra Asri

\subsection{Metode Pengumpulan Data}

Data yang diperlukan untuk penelitian dan digunakan sebagai variabel-variabel yang dianalisis dengan metode regresi linear berganda adalah data primer yang di dapat dari karateristik rumah 
tangga perumahan Griya Citra Asri Surabaya dan data sekunder didapat dari administrasi perumahan Griya Citra ASri Surbaya

\section{a. Data Primer}

Data primer merupakan data yang didapat langsung dari sumber asli dan tanpa perantara, umumnya berisi opini secara individu terhadap obyek yang sedang diteliti. Data primer diperoleh dengan membagikan form kuisioner yang telah diisi oleh responden seperti Data jumlah anggota keluarga, Data jumlah pendapatan rata-rata keluarga per bulan, Data jumlah pegawai, pelajar, dan mahasiswa, Data jumlah sepeda motor, Data jumlah mobil, Data jumlah perjalanan anggota keluarga per harikemudian dilakukan perekapan data. Sehingga hasil yang di peroleh berupa data.

b. Data Sekunder

Data sekunder merupakan data yang di dapat oleh peneliti melalui administrasi kelurahandan RW perumahan Griya Citra Asri surabaya. Umumnya berupa data jumlah anggota keluarga, pendapatan perbulan, jumlah pegawai, pelajar dan mahasiswa, jumlah sepeda motor, jumlah mobil, biaya transportas, jumlah waktu dan jarak tempuh perjalanan.

c. Studi Literatur

Metode pengumpulan data teori-teori dari beberapa sumber bacaan seperti buku, jurnal ilmiah, tugas akhir, dan sumber-sumber sejenit yang terkait dengan laporan bangkitan perjalanan.

d. Studi langsung

Membuat kuisioner untuk mendapatkan informasi yang di butuhkan dalam membuat permodelan. Informasi ini merupakan variabel yang berkaitan untuk tarikan perjalanan pada kawasan perumahan Griya Citra Asri sesuai studi kasus.

\section{e. Penentuan Sampel}

Metode pengambilan sampel ini menggunakanprobability sample melalui metode simple Random Sampling, yaitu memilih anggota sampel secara acak tanpa mempertimbangkan strata pada sampel tersebut. Pada penelitian kali ini peneliti mengambil populasi RW 07 yang berada di perumahan Griya Citra Asri Surabaya yang memiliki kepala keluarga sejumlah 650 kk. Kemudian dihitung menggunakan rumus Slovin untuk mengambil sejumlah sample dengan nilai tingkat kesalahan adalah 5\% dari hasil perhitungan tersebut diperoleh sampel sebanyak 247 KK.

\subsection{Teknik Analisis Data}

Dalam menganalisis dan mengelola data digunakan metode analisis regresi linier berganda, dengan menggunakan analisis statistika SPSS. Untuk mendapatkan model bangkitan perjalanan dengan bantuan SPSS21.

\section{a. Analisis regresi linier berganda}

Pada analisis regresi linear berganda menghubungkan satu variabel tidak bebas dengan dua atau lebih variabel-variabel bebas yang dianggap mempengaruhi variabel tidak bebas.

\section{b. Pengujian Statistik}

Pengujian model ini dilakukan untuk mengetahui tingkat keadaan model.Untuk analisis regresi pengujian model yang dilakukan adalah :

\section{- Uji Validitas}

Uji validitas ialah pengujian yang dilakukan terhadap isi atau konten dari suatu instrument. Pengujian ini bertujuan untuk mengukur ketepatan instrumen yang digunakan dalam suatu penelitian.

\section{- Uji Normalitas}

Pengujian normalitas dilakukan untuk mengetahui apakah variabel terdistribusi normal atau tidak.

- Uji korelasi (r)

Koefisien korelasi berfungsi untuk mengetahui hubungan antara variabel tidak bebas [4]

Tabel 1. Interval Koefisien Korelasi 


\begin{tabular}{lll}
\hline $\begin{array}{l}\text { No } \\
\cdot\end{array}$ & $\begin{array}{l}\text { Interval } \\
\text { Korelasi }\end{array}$ & Tingkat Hubungan \\
\hline 1 & $0,00-0,199$ & Sangat Rendah \\
2 & $0,20-0,399$ & Rendah \\
3 & $0,40-0,599$ & Sedang \\
4 & $0,60-0,799$ & Kuat \\
5 & $0,80-1,000$ & Sangat Kuat \\
\hline
\end{tabular}

- Uji - F Anova

Uji - F digunakan untuk menguji signifikasi dari parameter regresi secara keseluruhan atau bisa disebut juga untuk menguji kecocokan model.

- $\mathbf{U j i}-\mathbf{T}$

Uji - t dilakukan untuk melihat apakah parameter yang melekat pada variabel bebas cukup signifikan terhadap suatu konstanta (a) nol dan sebaliknya. Kalau signifikan, maka variabel bebas yang terkait dengan parameter harus ada dalam model. Uji - $\mathrm{t}$ bisa diterima apabila nilai $t_{\text {hitung }}>t_{\text {tabel }}$.

- Koefisien Determinasi $\left(\mathbf{R}^{2}\right)$

Koefisien determinasi digunakan untuk mengetahui kontribusi variabel bebas terhadap variabel terikat.

\section{Hasil dan Pembahasan}

\subsection{Uji Validitas}

Uji validitas dilakukan untuk mengetahui tingkat kesahihan dari hasil pengukuran suatu kuisioner, artinya uji validitas adalah sebuah pengujian untuk melihat kemampuan item pertanyaan atau instrumen dalam mengukur apa yang ingin diukur. Konsep dari uji validitas adalah uji korelasi dimana item pertanyaan atau instrumen dianggap valid ketika berkorelasi dengan skor totalnya. Hipotesis dari uji validitas adalah sebagai berikut.

$\mathrm{H}_{0}$ : Tidak ada korelasi antara variabel dengan skor total (tidak valid)

$\mathrm{H}_{1}$ : Terdapat korelasi antara variabel dengan skor total (valid)

Hasil dari uji validitas dapat dilihat pada Tabel 2 sebagai berikut.

Tabel 2. Uji Validitas

\begin{tabular}{ccc}
\hline Variabel & P-value Uji Validitas & Kesimpulan \\
\hline X1 & 0.004 & Item pertanyaan valid \\
X2 & 0.000 & Item pertanyaan valid \\
X3 & 0.000 & Item pertanyaan valid \\
X4 & 0.000 & Item pertanyaan valid \\
X5 & 0.000 & Item pertanyaan valid \\
X6 & 0.000 & Item pertanyaan valid \\
X7 & 0.000 & Item pertanyaan valid \\
Y & 0.000 & Item pertanyaan valid \\
\hline
\end{tabular}

Keputusan dapat dilihat berdasarkan nilai $p$-value pada hasil pengujian. Taraf kepercayaan penelitian ini adalah 95\%, maka taraf kesalahan $(\alpha)$ yang digunakan pada penelitian ini adalah $5 \%$ atau 0.05 . Sehingga apabila nilai $p$-value $<0.05$ maka Hipotesis $\mathrm{H}_{0}$ ditolak yang artinya menerima $\mathrm{H}_{1}$ bahwa item pertanyaan tersebut valid. Berdasarkan uji validitas yang telah dilakukan, bahwa semua item pertanyaan atau variabel memiliki $p$-value $<0.05$ artinya seluruh pertanyaan atau variabel tersebut dinyatakan valid. pada Tabel 2 variabel $\mathrm{X} 1, \mathrm{X} 2, \mathrm{X} 3, \mathrm{X} 4, \mathrm{X} 5, \mathrm{X} 6, \mathrm{X} 7$ dan $\mathrm{Y}$ dalam output spss21 di dapatkan hasil $p$-value yang disimpulkan bahwa item tersebut valid. 


\subsection{Uji Normalitas}

Uji normalitas data merupakan pengujian hipotesis untuk mengetahui apakah data yang diperoleh berdistribusi normal atau tidak. Uji normalitas dilakukan dengan menggunakan metode uji KolmogorovSmirnov karena sampel data $>50$ data. Hipotesis dari uji normalitas adalah sebagai berikut.

$\mathrm{H}_{0}$ : Data berdistribusi normal

$\mathrm{H}_{1}$ : Data tidak berdistribusi normal

Pengambilan keputusan dilihat berdasarkan nilai $p$-value pada hasil uji output SPSS21, apabila nilai $p$ value $<$ taraf kesalahan $(\alpha)$ yaitu $5 \%$ maka $\mathrm{H}_{0}$ ditolak yang artinya data tidak berdistribusi normal dan sebaliknya apabila nilai $p$-value $>$ taraf kesalahan $(\alpha)$ yaitu $5 \%$ maka $\mathrm{H}_{0}$ diterima yang artinya data berdistribusi normal. Hasil dari uji normalitas data dapat dilihat pada Tabel 3 sebagai berikut.

\begin{tabular}{ccc} 
Tabel 3. Hasil Uji Normalitas Variabel dengan Metode Kolmogorov-Smirnov \\
\hline Variabel & P-value Uji Normalitas & Keputusan \\
\hline X1 & 0.200 & Data berdistribusi normal \\
X2 & 0.200 & Data berdistribusi normal \\
X3 & 0.200 & Data berdistribusi normal \\
X4 & 0.200 & Data berdistribusi normal \\
X5 & 0.060 & Data berdistribusi normal \\
X6 & 0.200 & Data berdistribusi normal \\
X7 & 0.200 & Data berdistribusi normal \\
Y & 0.200 & Data berdistribusi normal \\
\hline
\end{tabular}

Dapat dilihat berdasarkan hasil uji normalitas diketahui bahwa seluruh variabel $\mathrm{X} 1, \mathrm{X} 2, \mathrm{X} 3, \mathrm{X} 4, \mathrm{X} 5, \mathrm{X} 6, \mathrm{X} 7$ dan $\mathrm{Y}$ di dapatkan hasil p-value yang disimpulkan bahwa item tersebut valid memiliki nilai $p$-value $>0.05$. Maka $\mathrm{H}_{0}$ diterima artinya seluruh pertanyaan atau variabel tersebut memenuhi asumsi normalitas data (Output SPSS21)

\subsection{Uji Korelasi}

Sebelum melakukan analisis regresi, perlu dipastikan bahwa variabel independen $\mathrm{X}$ memiliki hubungan yang signifikan dengan variabel dependen Y. Hipotesis dari uji korelasi adalah sebagai beirkut.

$\mathrm{H}_{0}$ : Tidak ada korelasi antara variabel $\mathrm{X}_{\mathrm{i}}$ dengan $\mathrm{Y} ; \mathrm{i}=1,2,3,4,5,6,7$

$\mathrm{H}_{1}$ : Terdapat korelasi antara variabel $\mathrm{X}_{\mathrm{i}}$ dengan $\mathrm{Y} ; \mathrm{i}=1,2,3,4,5,6,7$

Pengambilan keputusan dilihat berdasarkan nilai $p$-value pada hasil uji output spss21, apabila nilai $p$-value $<$ taraf kesalahan $(\alpha)$ yaitu $5 \%$ maka $\mathrm{H}_{0}$ ditolak yang artinya terdapat korelasi antara kedua variabel dan sebaliknya apabila nilai $p$-value $>$ taraf kesalahan $(\alpha)$ yaitu $5 \%$ maka $\mathrm{H}_{0}$ diterima yang artinya tidak terdapat korelasi antara kedua variabel. Hasil uji korelasi diberikan pada Tabel 4 sebagai berikut.

\begin{tabular}{cccl} 
Uji Korelasi & $\begin{array}{c}\text { Koefisien } \\
\text { Korelasi }\end{array}$ & $\begin{array}{c}\text { P-value Uji } \\
\text { Korelasi }\end{array}$ & Keputusan Uji Hipotesis \\
\hline X1 dengan Y & 0.161 & 0.011 & Memiliki korelasi signifikan \\
X2 dengan Y & 0.248 & 0.000 & Memiliki korelasi signifikan \\
X3 dengan Y & 0.186 & 0.003 & Memiliki korelasi signifikan \\
X4 dengan Y & 0.356 & 0.000 & Memiliki korelasi signifikan \\
X5 dengan Y & 0.255 & 0.000 & Memiliki korelasi signifikan \\
X6 dengan Y & 0.329 & 0.000 & Memiliki korelasi signifikan \\
X7 dengan Y & 0.767 & 0.000 & Memiliki korelasi signifikan \\
\hline
\end{tabular}

Berdasarkan Tabel 4. dapat diketahui bahwa seluruh variabel memiliki nilai memiliki $p$-value $<0.05$. Maka $\mathrm{H}_{0}$ ditolak artinya seluruh variabel $\mathrm{X}$ yaitu jumlah anggota keluarga (X1), jumlah penghasilan per bulan (X2), jumlah anggota keluarga bekerja (X3), jumlah keluarga bersekolah (X4), jumlah motor yang dimiliki (X5), jumlah mobil yang dimiliki (X6), jumlah jarak tempuh perjalanan (X7) memiliki korelasi yang signifikan terhadap variabel Y yaitu jumlah perjalanan (Output SPSS21). 


\subsection{Analisis Regresi}

Analisis Regresi dilakukan untuk membuat suatu model hubungan antara variabel $\mathrm{X}$ dengan Y yang dapat digunakan untuk memprediksi nilai Y. Hasil analisis dijelaskan sebagai berikut.

\section{a. Uji Signifikansi Pengaruh dari Parameter Regresi Secara Serentak (Uji F)}

Uji ini merupakan uji untuk melihat bagaimanakah pengaruh semua variabel independen yaitu jumlah anggota keluarga (X1), jumlah penghasilan per bulan (X2), jumlah anggota keluarga bekerja (X3), jumlah keluarga bersekolah (X4), jumlah motor yang dimiliki (X5), jumlah mobil yang dimiliki (X6) dan jumlah jarak tempuh perjalanan (X7) secara bersama-sama terhadap variabel dependennya yaitu jumlah perjalanan.

Tabel 5. ANOVA

\begin{tabular}{cccccc}
\hline Model & $\begin{array}{c}\text { Sum of } \\
\text { Squares }\end{array}$ & df & $\begin{array}{c}\text { Mean } \\
\text { Square }\end{array}$ & F & $\begin{array}{c}\text { P-value } \\
\text { (Sig.) }\end{array}$ \\
\hline Regression & 67.799 & 7 & 9.686 & 9966.700 & 0.000 \\
Residual & 0.232 & 239 & 0.001 & & \\
Total & $\mathbf{6 8 . 0 3 1}$ & $\mathbf{2 4 6}$ & & & \\
\hline
\end{tabular}

ANOVA pada Tabel 5 menunjukkan hasil uji $\mathrm{F}$ yaitu uji pengaruh atau signifikansi parameter regresi secara serentak. Hipotesis uji $\mathrm{F}$ diberikan sebagai berikut.

$H_{0}: \beta_{0}=\beta_{1}=\beta_{2}=\beta_{3}=\beta_{4}=\beta_{5}=\beta_{6}=\beta_{7}=0$ (Tidak ada variabel independen yang signifikan berpengaruh terhadap variabel dependen)

$H_{1}$ : Minimal ada satu $\beta_{i} \neq 0$ (Minimal terdapat satu variabel independen yang signifikan berpengaruh terhadap variabel dependen) $; \mathrm{i}=0,1,2,3,4,5,6,7$

Pengambilan keputusan dilihat berdasarkan nilai $p$-value atau nilai sig. pada output SPSS21. Apabila nilai sig. $<$ taraf kesalahan $(\alpha)$ yaitu 0.05 maka $\mathrm{H}_{0}$ ditolak dan sebaliknya apabila nilai sig. > taraf kesalahan $(\alpha)$ yaitu 0.05 maka $\mathrm{H}_{0}$ diterima. Tabel 5 menunjukkan nilai sig. dari hasil uji $\mathrm{F}$ adalah 0.000 yang lebih kecil dari 0.05 , maka $\mathrm{H}_{0}$ ditolak atau menerima $\mathrm{H}_{1}$ yang berarti bahwa berdasarkan uji secara serentak, terdapat minimal terdapat satu variabel independen yang signifikan berpengaruh terhadap variabel dependen.

\subsection{Uji Signifikansi Pengaruh dari Parameter Regresi Secara Parsial (Uji t)}

Uji parsial digunakan untuk mengetahui pengaruh dari signifikansi dari parameter regresi yang dilakukan secara parsial atau sendiri-sendiri.

Tabel 6. Uji t

\begin{tabular}{ccc}
\hline & B & P-value \\
\hline Konstanta & -0.808 & 0.000 \\
X1 & 0.156 & 0.000 \\
X2 & 0.083 & 0.000 \\
X3 & 0.166 & 0.000 \\
X4 & 0.665 & 0.000 \\
X5 & 0.165 & 0.000 \\
X6 & 0.170 & 0.000 \\
X7 & 0.091 & 0.000 \\
\hline
\end{tabular}

Berdasarkan Tabel 6 dapat dilihat nilai koefisien model regresi dari setiap variabel X. Berdasarkan 6 dapat dilihat nilai $\beta_{0}$ yaitu konstanta adalah sebesar -0.808 , nilai koefisien untuk variabel X1 yaitu $\beta_{1}$ sebesar 0.156 , nilai koefisien untuk variabel X2 yaitu $\beta_{2}$ sebesar 0.085 , nilai koefisien untuk variabel X3 yaitu $\beta_{3}$ sebesar 0.166 , nilai koefisien untuk variabel $\mathrm{X} 4$ yaitu $\beta_{4}$ sebesar 0.665 , nilai koefisien untuk variabel X5 yaitu $\beta_{5}$ sebesar 0.165 , nilai koefisien untuk variabel X6 yaitu $\beta_{6}$ sebesar 0.170 dan nilai koefisien untuk variabel X7 yaitu $\beta_{7}$ sebesar 0.091 . Besarnya koefisien tersebut menunjukkan besarnya perubahan variabel dependen Y yaitu jumlah perjalanan apabila nilai variabel independen X berubah. Signifikansi dari parameter $\beta$ dari setiap variabel $\mathrm{X}$ tersebut perlu diuji dengan uji t. Hipotesis uji $\mathrm{t}$ diberikan sebagai berikut. 
$H_{0}: \beta_{i}=0$ (Variabel $\mathrm{X}_{\mathrm{i}}$ tidak memberikan pengaruh yang signifikan terhadap variabel Y) $; \mathrm{i}=0,1,2,3,4,5,6,7$

$H_{1}: \beta_{1} \neq 0$ (Variabel $\mathrm{X}_{\mathrm{i}}$ memberikan pengaruh yang signifikan terhadap variabel $\mathrm{Y}$ ) ; i $=0,1,2,3,4,5,6,7$

Pengambilan keputusan dilihat berdasarkan nilai $p$-value atau nilai sig. pada output SPSS21. Apabila nilai sig. $<$ taraf kesalahan $(\alpha)$ yaitu 0.05 maka $\mathrm{H}_{0}$ ditolak dan sebaliknya apabila nilai sig. $>$ taraf kesalahan $(\alpha)$ yaitu 0.05 maka $\mathrm{H}_{0}$ diterima. Tabel 6 menunjukkan nilai $p$-value dari seluruh parameter $\beta$ dari setiap variabel $\mathrm{X}$ adalah 0.000 yang lebih kecil dari 0.05 , maka $\mathrm{H}_{0}$ ditolak yang berarti seluruh nilai $\beta$ tersebut signifikan. Oleh karena itu dapat disimpulkan bahwa ketujuh variabel $\mathrm{X}$ yang diteliti dalam penelitian ini yaitu jumlah anggota keluarga (X1), jumlah penghasilan per bulan (X2), jumlah anggota keluarga bekerja (X3), jumlah keluarga bersekolah (X4), jumlah motor yang dimiliki (X5), jumlah mobil yang dimiliki (X6) dan jumlah jarak tempuh perjalanan (X7) memiliki pengaruh yang signifikan terhadap variabel $\mathrm{Y}$ yaitu jumlah perjalanan.

\subsection{Model Regresi}

Setelah melakukan uji signifikansi parameter baik secara serentak dan secara parsial, maka dpat dibentuk model regresi yang terbentuk dari hasil analisis yang telah dilakukan. Model regresi yang terbentuk adalah sebagai berikut.

$\mathrm{Y}=-\mathbf{0 . 8 0 8}+0.156 \mathrm{X} 1+0.083 \mathrm{X} 2+0.166 \mathrm{X3}+\mathbf{0 . 6 6 5} \mathrm{X} 4+0.165 \mathrm{X5}+0.170 \mathrm{X6}+0.091 \mathrm{X} 7$

Berdasarkkan model yang terbentuk maka dapat dijelaskan hubungan sebagai berikut.

- Apabila variabel jumlah anggota keluarga (X1) bertambah 1 orang, maka variabel jumlah perjalanan (Y) akan mengalami peningkatan sebesar 0.156. Semakin banyak jumlah anggota keluarga (X1), maka jumlah perjalanan (Y) akan semakin bertambah karena hubungannya yang positif atau berbanding lurus.

- Apabila variabel jumlah pendapatan (X2) bertambah 1 juta per bulan, maka variabel jumlah perjalanan (Y) akan mengalami peningkatan sebesar 0.083. Semakin tinggi jumlah pendapatan (X2), maka jumlah perjalanan (Y) akan semakin bertambah karena hubungannya yang positif atau berbanding lurus.

- Apabila variabel jumlah anggota keluarga bekerja (X3) bertambah 1 orang, maka variabel jumlah perjalanan (Y) akan mengalami peningkatan sebesar 0.166. Semakin tinggi jumlah anggota keluarga bekerja (X3), maka jumlah perjalanan (Y) akan semakin bertambah karena hubungannya yang positif atau berbanding lurus.

- Apabila variabel jumlah anggota keluarga bersekolah (X4) bertambah 1 orang, maka variabel jumlah perjalanan (Y) akan mengalami peningkatan sebesar 0.665. Semakin tinggi jumlah anggota keluarga bersekolah (X4), maka jumlah perjalanan (Y) akan semakin bertambah karena hubungannya yang positif atau berbanding lurus.

- Apabila variabel jumlah motor yang dimiliki (X5) bertambah 1 buah, maka variabel jumlah perjalanan (Y) akan mengalami peningkatan sebesar 0.165. Semakin tinggi jumlah motor yang dimiliki (X5), maka jumlah perjalanan (Y) akan semakin bertambah karena hubungannya yang positif atau berbanding lurus.

- Apabila variabel jumlah mobil yang dimiliki (X6) bertambah 1 buah, maka variabel jumlah perjalanan (Y) akan mengalami peningkatan sebesar 0.170. Semakin tinggi jumlah mobil yang dimiliki (X6), maka jumlah perjalanan (Y) akan semakin bertambah karena hubungannya yang positif atau berbanding lurus.

- Apabila variabel jumlah jarak tempuh perjalanan (X7) bertambah 1 buah, maka variabel jumlah perjalanan (Y) akan mengalami peningkatan sebesar 0.091. Semakin tinggi jumlah jarak tempuh perjalanan (X7), maka jumlah perjalanan (Y) akan semakin bertambah karena hubungannya yang positif atau berbanding lurus.

Setelah model terbentuk, maka dapat dilihat pula nilai $\mathrm{R}^{2}$ atau koefisien determinasi. Yang menunjukkan sumbangan atau pengaruh yang diberikan seluruh variabel independen $\mathrm{X}$ dalam model terdadap variabel dependen Y. 
Tabel 7. Koefisien Determinasi

\begin{tabular}{cccc}
\hline $\boldsymbol{R}$ & $\begin{array}{c}\boldsymbol{R} \\
\text { Square }\end{array}$ & $\begin{array}{c}\text { Adjusted } \boldsymbol{R} \\
\text { Square }\end{array}$ & $\begin{array}{c}\text { Std. Error of the } \\
\text { Estimate }\end{array}$ \\
\hline 0.998 & 0.997 & 0.996 & 0.031 \\
\hline
\end{tabular}

Koefisien determinasi atau $\mathrm{R}^{2}$ yang didapat dari analisis regresi adalah sebesar 0.997 maka dapat dijelaskan bahwa variabel $\mathrm{Y}$ yaitu jumlah perjalanan dapat dijelaskan oleh variabelvariabel independen yaitu jumlah anggota keluarga (X1), jumlah penghasilan per bulan (X2), jumlah anggota keluarga bekerja (X3), jumlah keluarga bersekolah (X4), jumlah motor yang dimiliki (X5), jumlah mobil yang dimiliki (X6) dan jumlah jarak tempuh perjalanan (X7) sebesar $99.7 \%$, sedangkan $0.03 \%$ sisanya dijelaskan oleh variabel lain yang tidak dijelaskan dalam model (Output SPSS21).

\subsection{Jumlah Bangkitan}

Setelah melakukan analisis regresi, maka telah diperoleh persamaan model untuk memprediksi bangkitan perjalanan penduduk perumahan Griya Citra Asri Surabaya. Besarnya nilai variabel pada model didasari dengan nilai total tiap variabel dan nilai rata-rata pada tiap variabel yang diperoleh dari hasil survey dari total 247 sampel. Perhitungan total dan rata-rata setiap variabel $\mathrm{X}$ diberikan sebagai berikut.

Tabel 8. Nilai Total dan Rata-rata Variabel Independen

\begin{tabular}{ccc}
\hline Variabel & $\begin{array}{c}\text { Total } \\
\text { (247 sampel) }\end{array}$ & $\begin{array}{c}\text { Rata-rata } \\
\text { (247 sampel) }\end{array}$ \\
\hline X1 & 1236 & 5 \\
X2 & 1982.4 & 8.03 \\
X3 & 493 & 2 \\
X4 & 373 & 1.51 \\
X5 & 734 & 2.97 \\
X6 & 497 & 2.01 \\
X7 & 4482 & 18.15 \\
\hline
\end{tabular}

Berdasarkan model bangkitan pada sub bab 4.16, maka didapatkan perjalanan per unit rumah atau per KK dan total perjalanan penduduk perumahan Griya Citra Asri Surabaya. Perhitungan diberikan sebagai berikut.

- Bangkitan perjalanan per unit rumah atau per KK

$$
\begin{aligned}
& \mathrm{Y}=-0.808+0.156 \mathrm{X} 1+0.083 \mathrm{X} 2+0.166 \mathrm{X} 3+0.665 \mathrm{X} 4+0.165 \mathrm{X} 5+0.170 \\
& \mathrm{X} 6+0.091 \mathrm{X} 7 \\
& \mathrm{Y}=-0.808+0.156(5)+0.083(8.03)+0.166(2)+0.665(1.51)+0.165(2.97)+ \\
&0.170 .01)+0.091(18.15)=4.46 \approx 5 \text { perjalanan per unit rumah atau per KK per } \\
& \quad \text { hari }
\end{aligned}
$$

- Bangkitan perjalanan total penduduk Griya Citra Asri Surabaya

$$
\begin{aligned}
\mathrm{Y}= & -0.808+0.156 \mathrm{X} 1+0.083 \mathrm{X} 2+0.166 \mathrm{X} 3+0.665 \mathrm{X} 4+0.165 \mathrm{X} 5+0.170 \mathrm{X} 6+ \\
& 0.091 \mathrm{X} 7 \\
\mathrm{Y}= & -0.808+0.156(1236)+0.083(1982.4)+0.166(493)+0.665(373)+0.165(734) \\
& +0.170(497)+0.091(4482) \\
= & 1299.89 \approx 1300 \text { perjalanan total penduduk Griya Citra Asri Surabaya per hari }
\end{aligned}
$$

\section{Kesimpulan}

Berdasarkan hasil studi yang dilakukan terhadap Perumahan Griya Citra Asri Surabaya (GCA) kelurahan Kandangan, Kecamatan Benowo, Kabupaten Surabaya, maka dapat disimpulkan sebagai berikut :

Berdasarkan variabel jumlah anggota keluarga (X1), mayoritas respoden memiliki anggota keluarga $\geq 5$ orang karena responden mayoritas berusia 45 tahun. Apabila dilihat berdasarkan jumlah pendapatan (X2), mayoritas respoden memiliki jumlah pendapatan $\geq 6$ juta karena mayoritas responden bekerja di kawasan industri margomulyo. Apabila dilihat berdasarkan jumlah anggota keluarga bekerja (X3), mayoritas respoden memiliki jumlah anggota keluarga bekerja 2 orang karena mayoritas anggota keluarga yang bekerja hanya orangtua. Apabila dilihat berdasarkan jumlah anggota keluarga bersekolah 
(X4), mayoritas respoden memiliki jumlah anggota keluarga bersekolah 2 orang karena dipengaruhi dari orang tua yang berusia 52 tahun dan 35 tahun. Apabila dilihat berdasarkan jumlah motor yang dimiliki (X5), mayoritas respoden memiliki jumlah motor 3 buah karena dipengaruhi oleh anggota keluarga yang bekerja dan bersekolah. Apabila dilihat berdasarkan jumlah mobil yang dimiliki (X6), mayoritas respoden memiliki jumlah mobil 2 buah karena dipengaruhi oleh anggota keluarga yang bekerja. Apabila dilihat berdasarkan jumlah jarak tempuh perjalanan (X7), mayoritas respoden memiliki jumlah jarak tempuh perjalanan $>14 \mathrm{~km}$ karena dipengaruhi oleh anggota keluarga bekerja dan bersekolah. Kemudian apabila dilihat berdasarkan jumlah perjalanan (Y), mayoritas respoden memiliki jumlah perjalanan 4 kali karena dipengaruhi oleh jumlah anggota bekerja dan bersekolah.

Terdapat 2 faktor yang paling dominan dalam mempengaruhi bangkitan perjalanan di perumahan Griya Citra Asri Surabaya yaitu jumlah anggota keluarga bersekolah X4, jumlah mobil X6. Model bangkitan perjalanan penduduk perumahan Griya Citra Asri Surabaya sebagai berikut :

$\mathrm{Y}=-0.808+0.156+0.083+0.166+0.665+0.165+0.170+0.091$

Model yang dihasilkan tersebut hanya dapat digunakan untuk bangkitan penduduk perumahan Griya Citra Asri Surabaya (GCA) kelurahan Kandangan, Kecamatan Benowo, Kabupaten Surabaya

\section{Referensi}

[1] M. Fakhruriza Pradana, Rindu Twidi B, Muhamad Ferhad (2013). "Analisa permodelan bangkitan pergerakan pada perumahan pondok cilegon indah kota cilegon". Cilegon : Universitas Sultan Ageng Tirtayasa.

[2] Tamin, ofyar Z. 2000. "Perencanaan \& Pemodelan Transportasi". Bandung : ITB.

[3] Sugiyono. 2007. "Statistika Untuk Penelitian. Bandung" : CV. ALFABETA.

[4] Maria S. Pidor, Dolly W. Karels, Margareth E. Bolla (2018). "Bangkitan Perjalanan Dan Pola Pergerakan Penduduk Kecamatan Kelapa Lima Kota Kupang". Jurnal Teknik Sipil, vol. vII, no. 2, 119-130

[5] Rosmiyati A. Bella, Kharson Malaikosa, Linda W. Fanggidae (2013). "Permodelan Bangkitan Perjalanan Berbasis Rumah Tangga Di Kompleks RSS. Baumata, Kecamatan Taebenu, Kabupaten Kupang". Jurnal Teknik Sipil, Vol. II. No. 1.

[6] Riko Harnoto, Benny Mochtar (2017). "Analisa Bangkitan Perjalanan Pada Perumahan Elektrik Mas Di Kota Samarinda. Samarinda" : Universitas 17 Agustus 1945 Samarinda. 